\title{
Prospects for eliminating fossil fuels from the electricity and vehicle transport sectors in New Zealand
}

\author{
Jonathan D Leaver ${ }^{1, *}$, Luke HT Leaver ${ }^{2}$ \\ ${ }^{1}$ Unitec NZ, Auckland, New Zealand \\ ${ }^{2}$ Asia Pacific Energy Research Centre, Tokyo, Japan \\ *Corresponding author.Tel: +64 98494180, Fax: +64 98154372, E-mail: jleaver@unitec.ac.nz
}

\begin{abstract}
New Zealand is a small isolated country in the South Pacific with a population of 4.3 million people that has a strong commitment to reducing greenhouse gas emissions stemming both from its drive for global branding of principal export commodities and a desire to invest in new green technologies. New Zealand's renewable electricity generation reserve using biomass and wind alone is as much as 11 times the 2009 annual electricity demand. In this study the practical limits of fossil fuel reductions in the electricity and road transport sectors of the New Zealand economy are investigated using the multi-region partial equilibrium economic model UniSyD to examine a low carbon scenario in which oil reaches a maximum of US\$200/bbl in 2030 in conjunction with a carbon tax of US\$200 per tonne of carbon dioxide equivalent. In this scenario biofuel and electric drive vehicles are found to constitute $8 \%$ and $36 \%$ of the light vehicle fleet in 2050 respectively, with the balance of $56 \%$ still being fossil fuel vehicles. Government regulation is likely needed to reduce the proportion of fossil fuel vehicles to below $30 \%$ of the total fleet.
\end{abstract}

Keywords: Alternative fuel vehicle, battery electric, hydrogen fuel cell, emissions

\section{Introduction}

New Zealand is a small isolated country in the South Pacific with a population of 4.3 million people that has a strong commitment to reducing greenhouse gas emissions stemming both from its drive for global branding of principal export commodities and a desire to invest in new green technologies. As part of the commitment to reduce greenhouse gases New Zealand is one of the 187 countries to sign the Kyoto Protocol [1], one of 126 countries that agreed to the Copenhagen Accord [2], and in 2010, joined 28 other countries that have an emissions trading scheme [3].

In 2009 New Zealand produced 72.5\% of its electricity from renewable energy [4] with the government aiming to increase this to $90 \%$ by 2025 [5]. Based on data from [6] and [7] New Zealand's potential renewable electricity generation reserve using biomass and wind alone is as much as 11 times the 2009 annual electricity demand with this being reduced to a factor of four if a wholesale electricity price limit of $8.4 \mathrm{USc} / \mathrm{kWh}$ is imposed. This provides opportunity to consider excluding fossil fuels from the electricity generation and transport sectors except where necessary to provide stability to the national electricity grid.

Studies on the economic impacts of alternative vehicle technologies on the New Zealand economy ([8], [9], [10]) have shown that a hydrogen fuelled fleet offers significant savings over a long range $(320 \mathrm{~km})$ battery electric vehicle $(\mathrm{BEV})$ fleet. To achieve up to $80 \%$ reductions in greenhouse gas emissions from the transport sector a transition to all-electric vehicles will be necessary. This transition will include the adoption of a range of vehicle technologies [11].

Replacing fossil fuels in the electricity generation mix in New Zealand was shown to be possible for the period 2005-2007 [12]. The key factor in optimizing supply was the effective use of hydro in conjunction with wind. Wind energy spillage, peak load shifting and back-up fossil based peaking plant, were also important elements. 
In this study the practical limits of fossil fuel reductions in the electricity and road transport sectors of the New Zealand economy to 2050 are investigated using the multi-region partial equilibrium economic model UniSyD4.4. The term "practical limit" in the context of this study means the utilization of all the available renewable energy resources of New Zealand that are economically viable within the scenario parameters. These resources include hydro, geothermal, wind, biomass (lignocellulose, rape seed) and solar.

\section{Methodology}

To explore the practical limits of fossil fuel reductions in the electricity and road transport sectors two scenarios were constructed. Each scenario excluded plug-in hybrid vehicles (PHEV) on the basis that these are an intermediate technology between conventional internal combustion engine vehicles (ICEV) and full electric drive vehicles. The scenarios are:

(i) Fossil Future (FF) in which no electric vehicles except hybrids (HEV) compete with the ICEV fleet before 2050. The carbon tax is US\$15/t-CO $\mathrm{CO}_{2 \text { eq }}$ and the oil price rises at $2 \%$ per annum in real terms to a maximum of US\$120/bbl by 2030.

(ii) Renewables Future (RF) in which BEVs with a $320 \mathrm{~km}$ range and HFCVs compete for market share in the vehicle fleet along with HEVs. The carbon tax is US\$200/t- $\mathrm{CO}_{2 \text { eq }}$ and the oil price rises at $4.7 \%$ per annum in real terms to a maximum of US $\$ 200 / b b l$ by 2030. No coal fired fossil fueled electricity generation is permitted.

The scenarios were simulated using the multi-regional partial equilibrium model UniSyD4.4 [8]. This is a system dynamics based model with a high degree of technological specificity in the electricity generation and transport sectors of the New Zealand economy. Each energy sector considers existing technologies and those that are contending to come on-stream to 2050 such as co-generation of hydrogen and electricity from coal or natural gas with sequestration as an option [8]. The model contains about 1150 variables and equilibrates supply and demand in fortnightly time steps in four primary markets in 13 geographic regions of New Zealand. These four markets comprise electricity generation, hydrogen generation, lignocellulose from purpose grown forests and the vehicle fleet. The model incorporates dynamic interactions based on the elasticity of prices with demand. The primary energy resource base for the model consists of hydro, geothermal, wind, biomass (lignocellulose, rape seed), natural gas, coal and solar.

The electricity market regions generate, import and export electricity based on the price of regional production and grid transmission costs. Options for electricity generation or energy saving on a domestic scale include micro-cogeneration of electricity and heat using either hydrogen or natural gas along with rooftop photovoltaics and solar thermal water heating. Temporal fluctuations in wind are neglected.

In the hydrogen market there are four centralised plant types of biomass gasification, coal gasification, large steam methane reforming and coal co-generation of hydrogen and electricity with sequestration of emissions using a solid oxide fuel cell topping cycle. There are five sizes for each plant to match supply with change in demand. Plants in the electricity and hydrogen markets are built by extrapolating demand growth from the previous three years up to four years in the future.

In the lignocellulose market, supply from forests is directly related to the forest residuals and purpose grown forest supply curve based on data from [6]. The biomass cost is determined on a marginal pricing system set in competition between the use of biomass for hydrogen, 
bioethanol production and electricity generation. The decision to build a new biomass based plant is determined by the same mechanism as the hydrogen market.

The vehicle market model uses a standard logit choice, also known as a conditional logit model [13] to determine the market share of any particular vehicle technology. The market share is a function of elasticities of fuel cost, purchase price as shown in Fig. 1, maximum range and consumer driving distance.

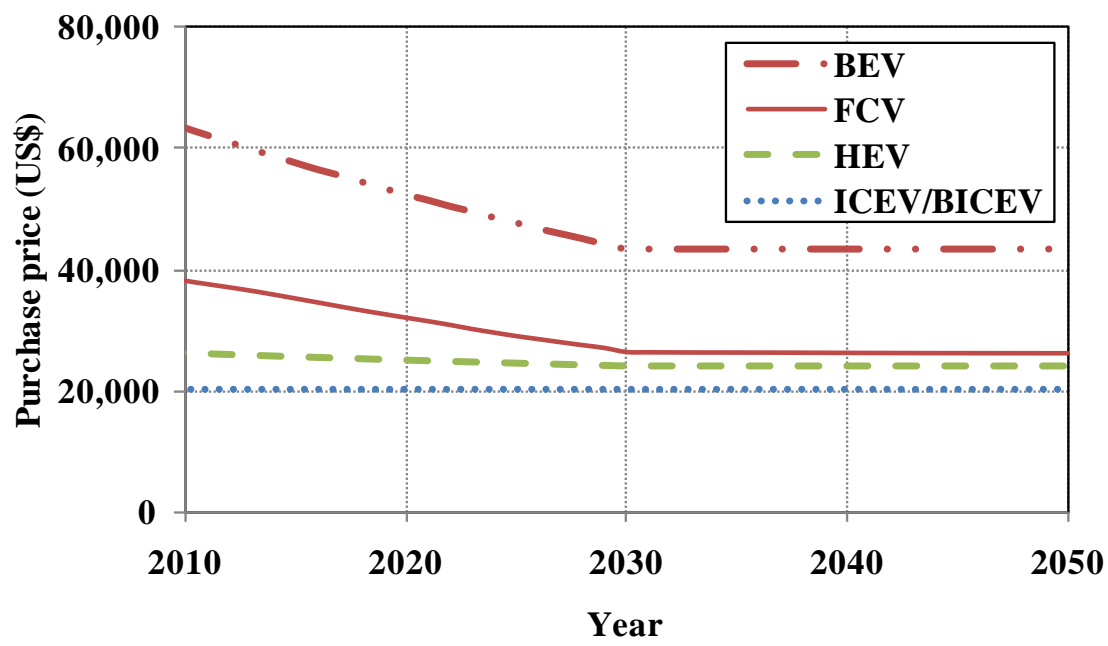

Fig. 1: Purchase price of alternative vehicles.

The standard logit choice model used in this study gives the market share of item $i\left(S_{i}\right)$, as a function of the price $\left(p_{i}\right)$, the price elasticity $\left(\beta_{i}\right)$, and the intrinsic preference parameter $\left(\gamma_{i}\right)$. The market share, $\mathrm{S}$, is given by [13]:

$S_{i}=\frac{e^{\left(\beta_{i} p_{i}-\gamma_{i}\right)}}{\sum_{j} e^{\left(\beta_{j} p_{j}-\gamma_{j}\right)}}$

A significant feature of Fig.1 is that the long term purchase price of BEVs with a $320 \mathrm{~km}$ range is likely to be $80 \%$ higher than the mean of the other options. In the vehicle market ICEVs, HEVs, FCVs, and BEVs compete for market share. As imported vehicles represented $48.6 \%$ of the light fleet in 2009 [14] the imported and New Zealand new light vehicle fleets are modeled separately.

\section{Results}

The model results for the Fossil Future and Renewables Future scenarios are shown in Figs. 2 and 3 respectively. Under the FF scenario Fig. 2a shows electricity generation from wind increases rapidly after 2025 with the mandated phasing out of fossil fuels. Wind penetration in 2050 is $35 \%$ of total generation by 2050 with hydro 38\%, geothermal $18 \%$ and $9 \%$ other renewable generation such as biogasification. In Fig. $2 \mathrm{~b}$ the electricity price averages about 7.0 USc/kWh after 2030 with the price spike in 2022 reflecting a short term electricity shortage due to the phasing out of coal production that is independent of carbon tax policy. In Fig. 2c, bioethanol production from forest resources provides fuel for $12 \%$ of the vehicle fleet by 2050 (Fig. 2e and 2f) with the balance of 88\% being fossil fueled. In Fig. 2d GHG emissions decrease by 7\% between 2010 and 2050 with a 34\% reduction during the period 2020 to 2030 with the reduction in fossil fueled electricity generation. Improving fuel 
economy in the vehicle fleet limits increases in GHG emissions for the period 2030 to 2050 to $17 \%$.
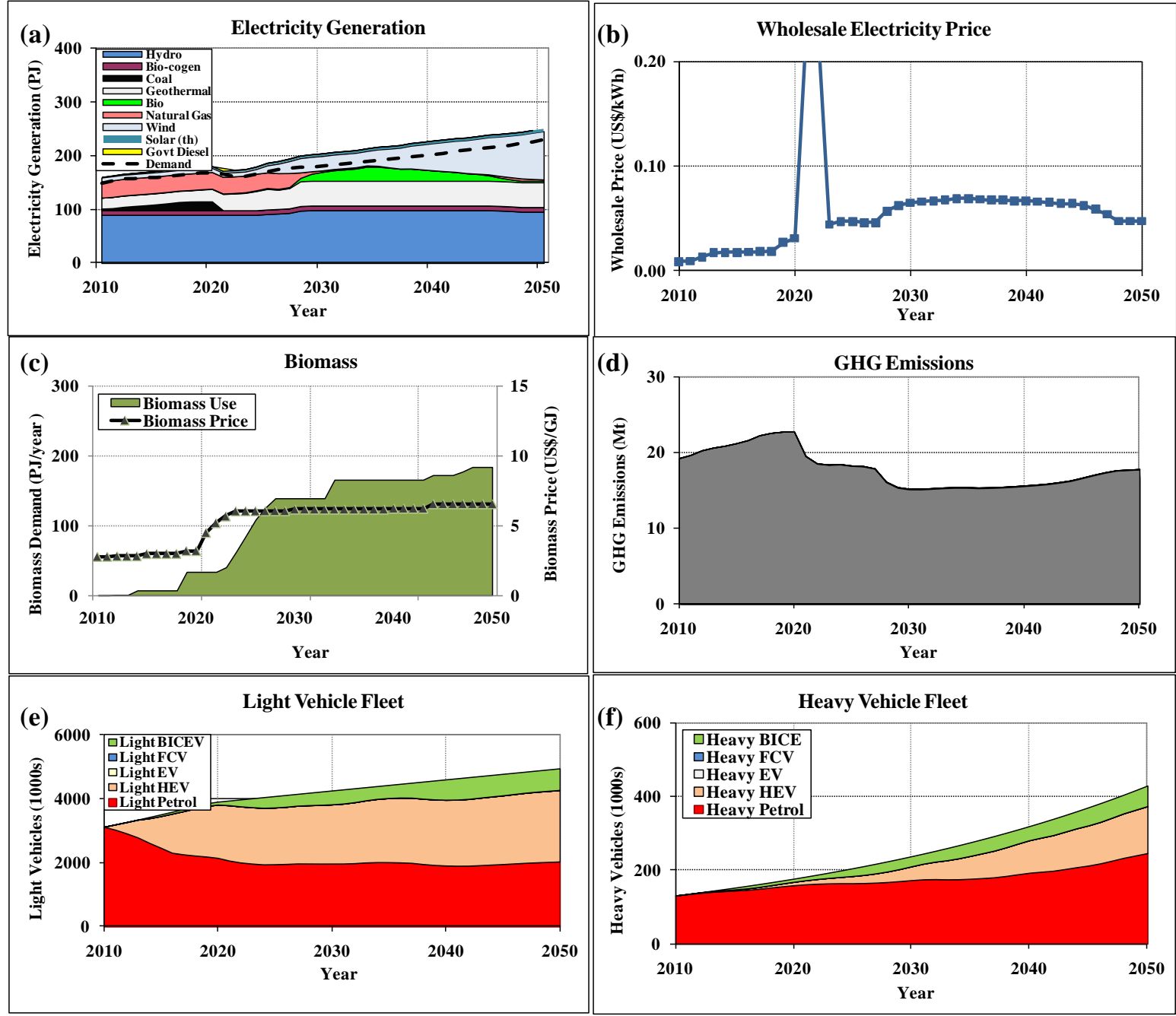

Fig. 2: For the Fossil Futures scenario: (a) Electricity generation profiles. (b) Hydrogen production profiles. (c) Wholesale electricity price. (d) Wholesale hydrogen price. (e) Biomass demand and price. (f) GHG emissions. (g) Light vehicle fleet. (f) Heavy vehicle fleet (g) Fuel economy. (h) Fuel cost per $k$ of travel.

Under the RF scenario in Fig. 3a the high carbon tax eliminates coal fired generation and natural gas generation ceases by 2018. By 2050 the generation profile consists of $41 \%$ wind, $36 \%$ hydro, $14 \%$ geothermal and $9 \%$ other renewable generation such as biogasification. Total renewable generation is $97 \%$. In Fig. 3b the electricity price rises to a high of 13 USc/kWh in 2013 with the sudden rise in carbon tax from US $\$ 15 / \mathrm{t}-\mathrm{C}$ to US $\$ 200 / \mathrm{t}-\mathrm{C}$. Prices average about 7.2 USc/kWh after 2030. In Fig. 3c hydrogen production commences with forecourt electrolysis in 2015 with large scale hydrogen production from biogasification commencing in 2020. Fig. 3d shows that the hydrogen production price is close to US $\$ 5.00 / \mathrm{kg}$ after 2020. In Fig. 3e biomass use rises sharply from 2016 to 2020 as a primary fuel for hydrogen production by biogasification. In Fig. 3d, GHG emissions decrease by 58\% between 2010 and 2050. In Fig. 3g light BICEVs, HFCVs, and EVs constitute 8\%, 28\% and $8 \%$ respectively of the light vehicle fleet in 2050, with the balance of $56 \%$ being ICEVs and HEVs. In Fig. 3h, heavy BICEVs and HFCVs constitute $14 \%$ and $44 \%$ respectively of the heavy vehicle fleet in 2050, with the balance of $42 \%$ being ICEVs and HEVs. 

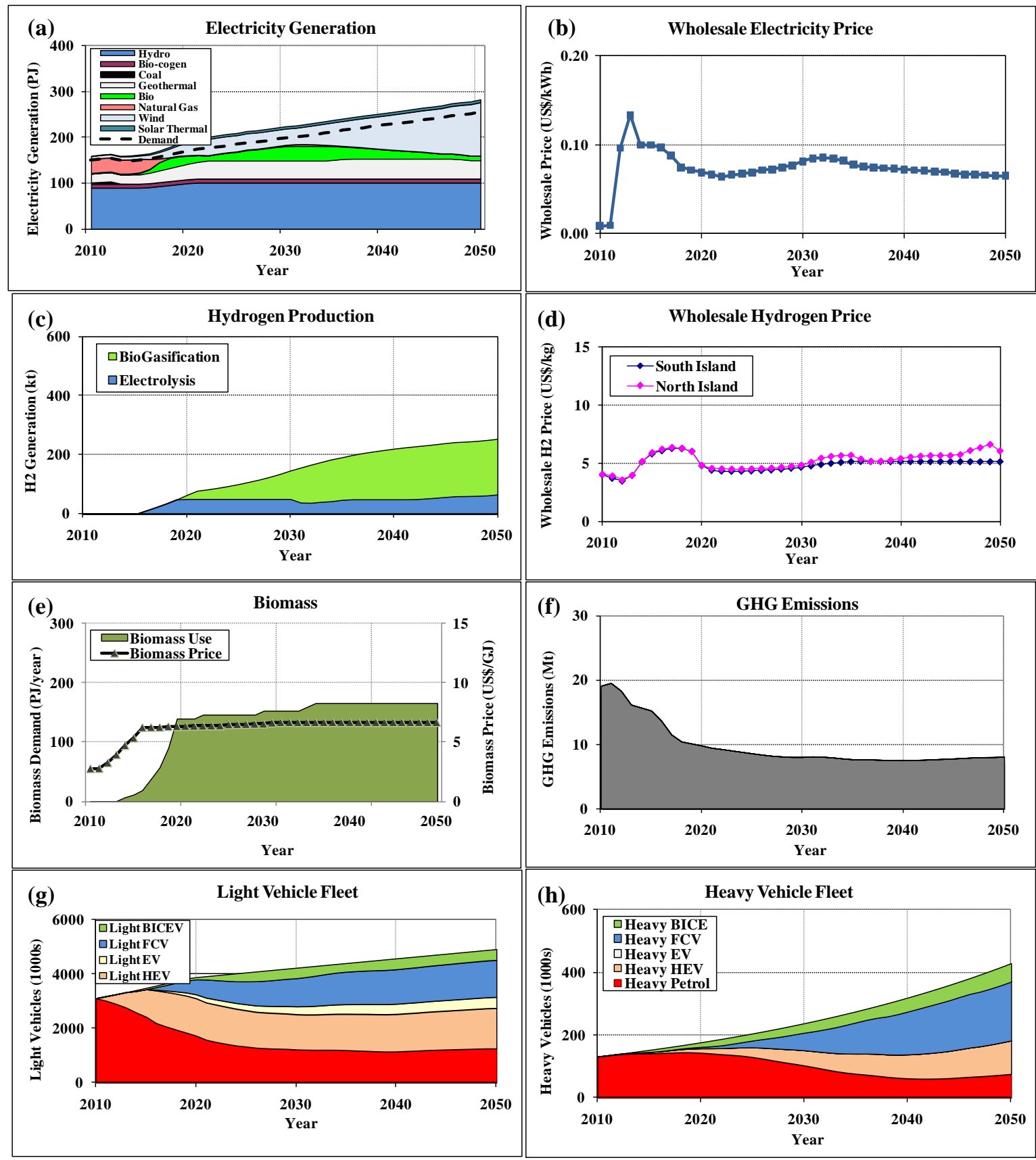

Fig. 3: For the Renewables Future scenario: (a) Electricity generation profiles. (b) Wholesale electricity price. (c) Hydrogen production profiles. (d) Wholesale hydrogen price. (e) Biomass demand and price. (f) GHG emissions. (g) Light vehicle fleet. (f) Heavy vehicle fleet (g) Fuel economy. (h) Fuel cost per $k$ of travel.

\section{Discussion}

Two primary consequences emerge from a comparison of the Fossil Future and Renewables Future scenarios. Firstly in 2050 in both scenarios all generation excluding backup peak load generation is renewable. The only effect of the high carbon tax in the RF scenario is to reduce geothermal generation by about $4 \%$ and replace this with wind. All GHG emissions are from the vehicle fleets. GHG emissions in the RF scenario are 54\% less than in the FF 
scenario by 2050 which equates to a $54 \%$ reduction by weight in fossil vehicle fuel. Secondly the proportion of light ICEVs under the RF scenario of 56\% is 32\% less than that under the FF scenario of $88 \%$. The fact that the combined penetration of ICEV and HEV in the RF scenario remains high at $56 \%$ is a result of the improving fuel economy of ICEVs and HEVs that enhances the competitiveness of these technologies and delays their replacement by all electric BEV and HFCV technologies. Reducing the penetration of ICEV and HEV to less than $30 \%$ of the total fleet may require government regulation to encourage adoption of electric vehicles. The primary focus of any regulation should be to reduce the purchase price of electric vehicles with subsidies while recovering the subsidy as a fuel tax. The motive behind this is that purchasers value an incremental reduction in purchase price at twice that of a reduction in running costs [15].

The average electricity price under RF remains stable at about $7.2 \mathrm{USc} / \mathrm{kWh}$ despite the increased electricity demand for hydrogen production by electrolysis and subsequent recharging of electric vehicles. This increase in electricity price is buffered by the large wind resource available at less than $8.4 \mathrm{USc} / \mathrm{kWh}$ referred to earlier in this study.

Wind penetration in the RF scenario is $41 \%$ by 2050 which poses significant issues for the stability of New Zealand's electricity grid. In Denmark the Danish Transmission System Operator is planning for up to $50 \%$ wind penetration in the transmission system [16]. However New Zealand cannot import electricity from neighboring countries.

Mason et al. [12] examined wind penetration in the New Zealand electricity system of up to $35 \%$ during $2005-2007$ when demand totaled $54 \%$ of expected demand in 2050 . The study concluded that penetration rates of $19 \%$ could be achieved by utilizing the existing hydro system to balance periods of low wind generation with almost no reduction in electrical energy from hydro generation.

Wind penetration of $18 \%$ has been estimated [17] to incur integration costs of $0.6 \mathrm{USc} / \mathrm{kWh}$ as shown in Table 1.

Table 1. Wind integration cost (adapted from [17]).

\begin{tabular}{lccc}
\hline \multicolumn{1}{c}{ Year } & 2010 & 2020 & 2030 \\
\hline Installed wind power capacity (MW) & 634 & 2066 & 3412 \\
Wind energy (PJ) & 8.3 & 24.1 & 39.1 \\
Wind energy as \% of total generation & 5 & 12.5 & 18 \\
\hline Additional wind integration cost (USc/kWh) & 0.14 & 0.14 & 0.61 \\
\hline
\end{tabular}

Recent wind integration studies [17, 18] suggest enough standby generation must be available to meet a 'no wind' scenario. Analysis of a 19-year daily synthetic wind speed dataset [19] showed that no wind generation is likely to occur for two days every three years under a geographically diverse wind portfolio. In order to cater for the 'no wind' scenario requirement at $41 \%$ wind penetration in 2050 , New Zealand will require active demand side management, smart flexible gas contracts and peaking based hydro management coupled with fast start standby thermal generation. This could include remote shut-down of selected hot water heating installations, and short term diversion of electricity and gas supplies from selected large industrial electricity users such as aluminum [20] and methanol [21] production plants. Diversion from large industrial plants has the potential to provide additional backup electricity generation of up to $50 \%$ and $66 \%$ respectively of predicted wind generation in 2050 under the RF and FF scenarios. Further measures may involve a mixture of pumped hydro storage using off peak electricity, or changing the operating limits of hydro lakes for very short periods. 
To ensure grid stability a number of load balancing generation and load shifting options will be needed. Load balancing options would principally include hydro with support from fossil fuelled peaking plants. Load shifting options could include remote shut-down of selected hot water heating installations, pumped hydro storage using off peak electricity, and smart metering that allows real time electricity billing to encourage fast consumer response to electricity price.

This study used an upper bound carbon tax of US\$200/t-C to examine renewable energy penetration limits. Marginally lower penetration rates of renewable energy may be possible with a carbon tax of US\$100/t-C although a detailed study of this option is outside the scope of this paper.

\section{Conclusions}

New Zealand's has the potential to achieve over $90 \%$ electricity generation from renewables by 2050 but maintaining or exceeding this target to 2050 will require complex integration of peak load backup generation to balance the variability of wind generation. This target is largely independent of the carbon tax due to the large and economically viable wind resource. In the vehicle fleet, in the absence of plug-in hybrid vehicles and without government regulation, $44 \%$ of the light vehicle fleet is expected to be electric drive by 2050 . The penetration rates of electric vehicles will be enhanced with purchase price subsidies capitalised from fuel taxes.

\section{References}

[1] United Nations Framework Convention on Climate Change, Status of Ratification of the Kyoto Protocol, http://unfccc.int/essential_background/kyoto_protocol/status_of_ratification/ items/5524.php. Accessed 1 October 2010.

[2] United Nations Framework Convention on Climate Change, Report of the Conference of the Parties on its fifteenth session, held in Copenhagen from 7 to 19 December 2009. Report 3F0C CMCa/rCchP /22001009 /11, 30 March 2010. p. 36.

[3] New Zealand Ministry for the Environment. The New Zealand Emissions Trading Scheme. http://www.climatechange.govt.nz/emissions-trading-scheme/. Accessed 1 October 2010.

[4] New Zealand Ministry of Economic Development, New Zealand Energy Data File: 2009 Calendar Year Edition, ISSN 1177-6676, 2010, p. 174.

[5] New Zealand Ministry of Economic Development, Draft New Zealand Energy Strategy: Developing our energy potential, ISBN 978-0-478-35862-9, 2010, p. 34.

[6] Scion, Bioenergy Options for New Zealand: Situation Analysis, ISBN 0-478-11019-7, 2007, p. 83.

[7] Connell Wagner, Transmission to Enable Renewables: Economic wind resource study, Report 31362/001, 2008, p. 27.

[8] J.D. Leaver, K.T. Gillingham, L. Leaver, Assessment of primary impacts of a hydrogen economy in New Zealand using UniSyD. International Journal of Hydrogen Energy 34 (7), 2009, pp. 2855-2865. 
[9] J.D. Leaver, K.T. Gillingham, Economic impact of the integration of alternative vehicle technologies into the New Zealand vehicle fleet. Journal of Cleaner Production, 18, 2010, pp. 908-916.

[10] R. Whitney, T. Clemens, A. Gardiner, J. Leaver, Transitioning to a Hydrogen Economy in New Zealand: An EnergyScape Project, Proc. XXI World Energy Congress, Montreal, 2010, p. 20.

[11]C. Thomas, Transportation options in a carbon-constrained world: Hybrids, plug-in hybrids, biofuels, fuel cell electric vehicles, and battery electric vehicles, International Journal of Hydrogen Energy 34, 2009, pp. 9279-9296.

[12]I.G. Mason, A 100\% renewable electricity generation system for New Zealand utilizing hydro, wind, geothermal and biomass resources, Energy Policy, 38, 2010, pp. 3973-3984.

[13]D.L. McFadden, Conditional Logit Analysis of Qualitative Choice Behavior. In P. Zarembka (ed.), Frontiers in Economics, 1973, New York: Academic Press, pp. 105-142.

[14] Ministry of Transport, The New Zealand Vehicle Fleet: Annual Fleet Statistics 2009, ISBN978-0-478-07228-0, 2010, p. 68.

[15] K.E. Train, EM Algorithms for nonparametric estimation of mixing distributions, Journal of Choice Modelling, 1(1), pp. 40-69.

[16]K. Sperling, F. Hvelplund, B. Vad Mathiesen. Evaluation of wind power planning in Denmark: Towards an integrated perspective, Energy (in press), 2010, p.12.

[17]G Strbac, D Pudjianto, A Shakoor, MJ Castro. New Zealand Wind Integration Study. Meridian Energy, April 2008. Accessed 8 November 2010.

http://www.meridianenergy.co.nz/NR/rdonlyres/345B3A36-1434-4CAF-95AC-. 10.

[18]B Smith, Wind integration - the long view, Report. The New Zealand Electricity Authority, April 2009.

[19] New Zealand Electricity Commission. Analysis of wind integration - synthetic wind data. April, 2009, http://www.ea.govt.nz/industry/modelling/analysis-of-wind-integration/. Accessed 17 November 2010.

[20]A. Bennett, Meridian boss hails deal with smelter, http://www.nzherald.co.nz/energy/news/article.cfm?c_id=37\&objectid=10467340. Accessed 8 November 2010.

[21] Contrafed Publishing Co. Ltd, A train in want of gas, Energy NZ, No.11 2009. 